\title{
Is tacrolimus more likely to induce diabetes mellitus than ciclosporin in heart transplant patients?
}

\author{
Anisha Jagpal', Sudeep Das $\mathrm{De}^{2}$, Sanjeet Singh Avtaar Singh ${ }^{2}$, Alan Kirk \\ ${ }^{1}$ College of Medical, Veterinary and Life Sciences, University Avenue, University of Glasgow, Glasgow G12 8QQ, UK. \\ ${ }^{2}$ Department of Cardiothoracic Surgery, Golden Jubilee National Hospital, Glasgow G81 4DY, UK.
}

Correspondence to: Mr. Sanjeet Singh Avtaar Singh, Department of Cardiothoracic Surgery, Golden Jubilee National Hospital, Glasgow G81 4DY, UK. E-mail: sanjeetsingh@nhs.net

How to cite this article: Jagpal A, Das De S, Avtaar Singh SS, Kirk A. Is tacrolimus more likely to induce diabetes mellitus than ciclosporin in heart transplant patients? Vesse/ Plus 2018;2:24. http://dx.doi.org/10.20517/2574-1209.2018.27

Received: 28 Apr 2018 First Decision: 23 Jul 2018 Revised: 25 Jul 2018 Accepted: 2 Aug 2018 Published: 13 Sep 2018
Science Editors: Mario F. L. Gaudino, Cristiano Spadaccio Copy Editor: Huan-Liang Wu Production Editor: Zhong-Yu Guo

\begin{abstract}
Aim: Immunosuppression has evolved since the first successful orthotopic heart transplant 50 years ago. Currently, calcineurin inhibitors lie at the focal point of the immunosuppressive regimen. However, these drugs exhibit a variety of side effects, including hyperglycaemia. This in turn compounds the risk of cardiovascular disease. There is conflict around which calcineurin inhibitor, tacrolimus or ciclosporin, is more likely to induce diabetes.
\end{abstract}

Methods: A retrospective analysis of data from 52 patients who had received a heart transplantation at the Scottish heart transplant unit between January 2011 and August 2017. All patients received a combination immunosuppressive regimen consisting of mycophenolate mofetil, corticosteroids and either tacrolimus or ciclosporin. Fasting glucose levels were compared every 3 months after transplantation for a year. HbA1c was collected and compared at one interval during follow-up postoperatively. Statistical analysis was achieved using Students t-test for continuous variables and Chi-squared test for categorical variables.

Results: The drug regimens remained unchanged in the two cohorts over the study period. The fasting glucose of tacrolimus treated patients was higher over the 12-month period compared to ciclosporin treated patients ( $7.3 \pm 1 \mathrm{vs}$. $5.9 \pm 0.5, P=0.017)$. The results were significantly higher in the tacrolimus group at 9 months $(P=0.013)$. In contrast to these findings, $\mathrm{HbA1c}$ of the tacrolimus group was lower than the ciclosporin group, although there was no significant difference ( $38 \pm 11.4$ vs. $43 \pm 1.3, P=0.104)$.

Conclusion: This study suggests a relationship between tacrolimus and rising fasting glucose among heart transplant population. However, a longer follow-up and control of confounding variables is required to denote the long-term impact of immunosuppression related diabetes in heart transplant patients.

Keywords: Immunosuppression, heart transplantation, tacrolimus, ciclosporin, diabetes
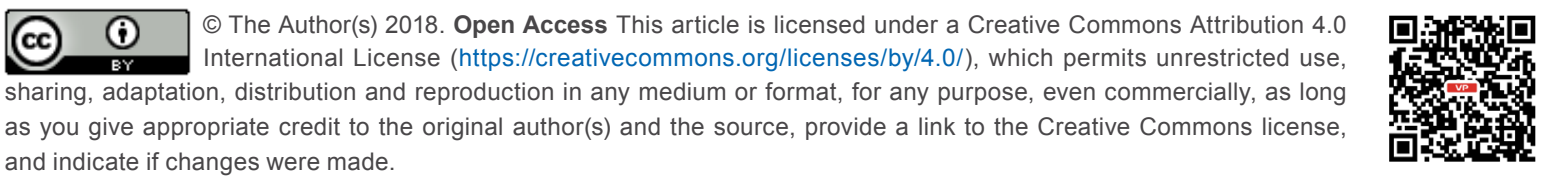


\section{INTRODUCTION}

Over the past 50 years, heart transplantation has evolved to become an acceptable treatment for end-stage heart failure. Immunosuppression has been pivotal to the success of this procedure. Many drugs have been involved in post-transplant immunosuppressive regimens. However, current guidelines recommend the use of calcineurin inhibitors, tacrolimus and ciclosporin. Due to the potency of these drugs, patients are prone to a variety of side effects including diabetes. Preventing post-transplant diabetes mellitus (PTDM) is an important element of successful immunosuppression in cardiac transplantation, as uncontrolled diabetes is associated with cardiovascular morbidity and mortality. This can be detrimental to heart transplant recipients as they are already at risk of cardiac allograft vasculopathy (CAV).

The aim of this paper is to retrospectively analyse the possibility of developing diabetes mellitus in heart transplant patients who have been treated with either a ciclosporin or tacrolimus-based regimen. This will be done by focusing on fasting glucose and HbA1c levels in 52 patients up to a year after transplantation.

\section{History of heart transplantation}

In 1967, Barnard ${ }^{[1]}$ performed the first successful human-to-human heart transplant in Cape Town, South Africa. The techniques used during this operation were created by Dr. Norman Shumway several years earlier and are still used in modern times ${ }^{[1]}$. Although a breakthrough in science at the time, the patient died of Pseudomonas pneumonia on the 18th day postoperatively ${ }^{[1]}$. This highlighted concerns surrounding immunosuppressive regimen, an issue which would remain prevalent for subsequent years.

A year on from Barnard ${ }^{[1]}$,s success, more than 100 cardiac transplants were performed at transplant centres around the world. But due to the high risk of complications, the procedure soon declined with only 9 taking place in 1971. During this time, one-year survival was $30 \%{ }^{[2]}$. A key advancement in rejection monitoring was the introduction of endomyocardial biopsy ${ }^{[3]}$ and the classification of histological rejection ${ }^{[4]}$. This allowed clinicians to combine clinical and histological findings to make the diagnosis of rejection more accurate. Worldwide interest in heart transplantation was revived in the 1980s after an immunological milestone, the introduction of ciclosporin A.

Between April 2016 and March 2017, 197 heart transplants were performed in the UK ${ }^{[5]}$ with one-year survival over $80 \%{ }^{[6]}$. This is a testament to the progress made since the 1970's. Nevertheless, there are still serious challenges facing the field, limiting the success of heart transplantation. Such barriers include $\mathrm{CAV}$, a type of chronic rejection that results in hardened arteries. This can compromise long term survival of the cardiac allograft and ultimately lead to cardiac arrest. Another major barrier is created by chronic immunosuppression, which can result in drug induced complications including diabetes mellitus ${ }^{[7]}$.

\section{Overview of rejection immunology}

Complex mechanisms of immunity pose a significant barrier to successful transplantation. In cardiac transplantation, the response to alloantigens is mediated by host T-cells. Peptide antigens are presented to T-cell receptors in the context of major histocompatibility complex, by antigen-presenting cells ${ }^{[8]}$. This binding leads to an increase in cytoplasmic calcium ions, which in turn activates the protein phosphatase, calcineurin. When activated, calcineurin dephosphorylates nuclear factor of activated T-cells (NFAT) ${ }^{[9]}$. Following this, NFAT triggers the upregulation IL-2 expression, leading to T-cell stimulation.

The adaptive response is efficiently suppressed by conventional drugs. But, when unsuccessful, alloimmune response can lead to destruction of the allograft (rejection). Rejection is categorised into three major types: hyperacute, acute and chronic. Due to effective screening (HLA and ABO blood-group cross-matching) on transplant recipients, hyperacute rejection is rare ${ }^{[10]}$. Although acute and chronic rejection are more common, the mechanisms involved are incompletely understood. There is, however, a variety of immunesystem components involved, including the T-cell response mentioned above ${ }^{[11]}$. 


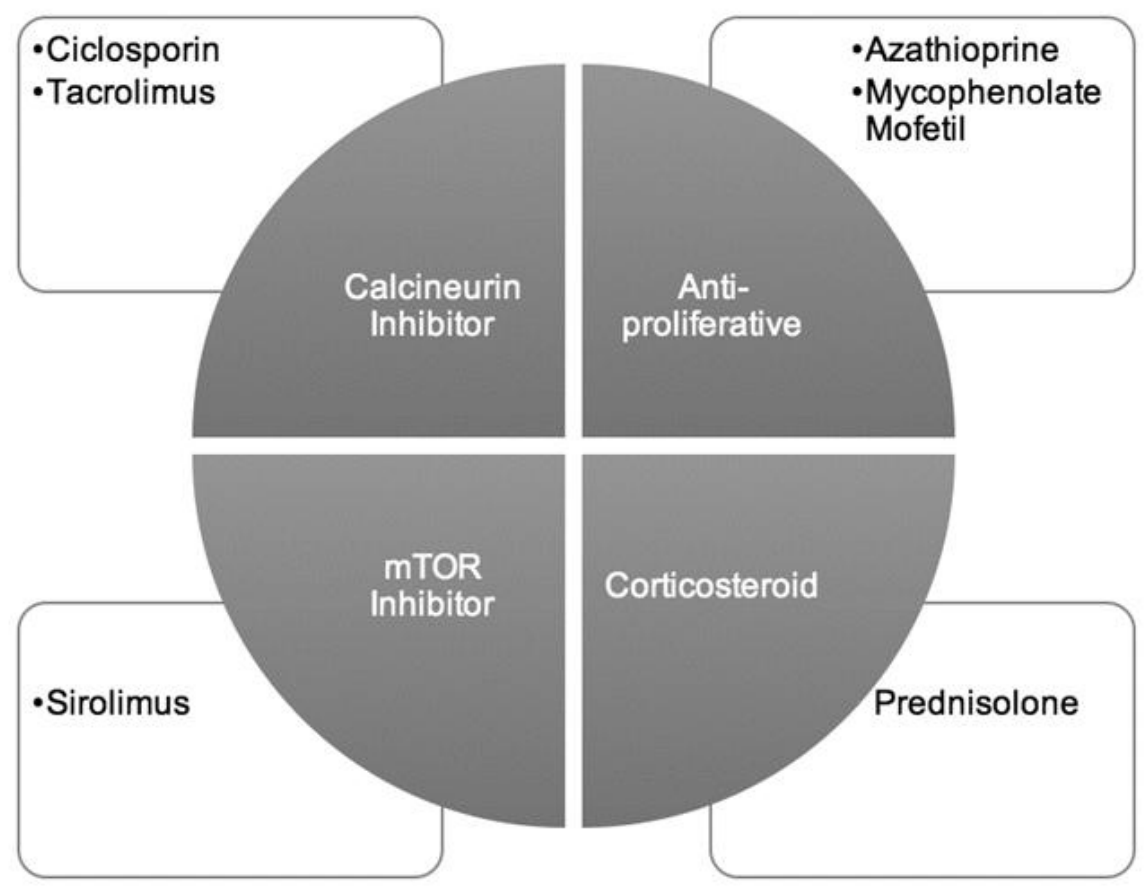

Figure 1. Four drug groups that make up the foundation of maintenance immunosuppression in heart transplantation

Despite the combination drug regimen targeting different stages of the immune response, illustrated in Figure 1, patients are still at risk of rejection. From 2010, 24\% of heart transplant recipients have experienced rejection ${ }^{[12]}$. This suggests there is room for more pharmacological discovery in this area.

\section{Immunosuppression regimens in transplantation}

Immunosuppression aims to dampen the immune response in order to sufficiently permit engraftment of the transplant, while simultaneously being suitably specific such that other protective immune responses remain intact. This requires a complementary combination of medication that optimise immunosuppression while decreasing toxicity. To create this balance in regimen, drugs are provided at different doses and timepoints so their effects are maximised.

Immunosuppressive treatment consists of induction and maintenance regimens. Induction therapy is intense and occurs before, during and after transplantation in aim to markedly reduce rejection in early postoperative period. Rabbit derived lympholytic agent, anti-thymocyte globulin (rATG) is a standard induction drug given postoperatively. Immediate postoperative rATG therapy allows CNIs to be introduced later. CNIs are nephrotoxic, so this action avoids exacerbation of renal dysfunction. Batches of rATG vary in potency, thus in order to assess the effectiveness, patients T cells should be monitored with flow cytometry ${ }^{[13]}$.

Maintenance therapy consists of a combination of drugs including: an antiproliferative, a calcineurin inhibitor (CNI) and steroids. Although maintenance regimens are continually evolving, corticosteroids have remained at the core since the first heart transplantation. However, due to their significant side effects, the duration and dosage of corticosteroids has decreased with time ${ }^{[14]}$. To combat this issue, combination therapy has moved towards targeting steps in T-cell activation, permitting lower doses for each individual drug.

Antiproliferative agents, Mycophenolate Mofetil (MMF) and Azathioprine, operate alongside other drugs to target the proliferation of $\mathrm{T}$ - and $\mathrm{B}$-cells, resulting in diminished cytotoxic T-cell respons ${ }^{[15,16]}$. MMF is recommended over due to its decreased incidence of rejection and $\mathrm{CAV}^{[17,18]}$. mTor inhibitors, such as Sirolimus, also target T-cell proliferation and are an effective alternative for CNI in patients with CNI 
induced nephrotoxicity ${ }^{[19]}$.

\section{Ciclosporin}

The discovery of ciclosporin in the early 1970s revolutionised the field of transplantation. Initially developed as an anti-fungal, the potent immunosuppressive properties of ciclosporin were first recognised in 1986 (Borel, 1986). Ciclosporin was approved for use in kidney transplantation in 1979. This dramatically improved the mortality of transplant patients and provided sufficient evidence to permit approval for use in heart transplantation in 1980. Five years after introducing the drug to cardiac transplant recipients, Shumway's group reported a 1-year survival rate of $83 \%{ }^{[20]}$. In 1994 , the original oil-based drug was replaced by a new micro-emulsion formulation (Neoral, Novartis). This provided greater bioavailability and more predictable pharmacokinetics, enhancing the role of ciclosporin in immunosuppression ${ }^{[21]}$. The use of ciclosporin in transplantation has led to a steady increase in survival, with worldwide 1-year survival now approaching $90 \%{ }^{[22]}$.

The calcineurin inhibitor, ciclosporin inhibits T-cell proliferation by blocking its activation. When entering lymphocytes, ciclosporin binds to cyclophilin, a type of immunophilin. This ciclosporin-cyclophilin complex binds to and inhibits the action of calcineurin. As a result, the IL-2 transcription cascade is halted. This ultimately blocks T-cell activation, preventing allograft rejection process.

\section{Tacrolimus}

Tacrolimus, a macrolide antibiotic, was found to possess potent immunosuppressive qualities in 1984. The compound was first approved for use in transplantation in Japan, $1993^{[23]}$. Due to its decreased incidence of rejection when combined with MMF, tacrolimus has surpassed ciclosporin to become the cornerstone of immunosuppressant therapy today ${ }^{[24]}$. Over $70 \%$ of patients worldwide are on a tacrolimus and MMF combination therapy, further highlighting the superiority of tacrolimus ${ }^{[12]}$.

Tacrolimus exhibits similar immunosuppressive activity to that of ciclosporin. However, tacrolimus inhibits calcineurin through binding to a different immunophilin, FK506 binding protein (FKBP12). Tacrolimus is also effective as a rescue rejection therapy ${ }^{[25]}$.

Although CNIs play a critical role in the preservation of allograft function, these drugs cause a variety of side effects, including hyperglycaemia. This in turn can result in significant morbidity and reduced quality of life ${ }^{[26]}$.

\section{Post-transplant diabetes mellitus}

Diabetes is a metabolic disorder characterised by chronic hyperglycaemia, resulting from defects in insulin secretion, insulin action, or both ${ }^{[27]}$. There are several diagnostic tests for diabetes shown in Table 1, each test is used alongside any symptoms a patient is experiencing ${ }^{[28]}$. Although it has been proposed that PTDM could be a distinct entity, the natural history of diabetes after transplantation resembles type 2 diabetes ${ }^{[2]}$. Since the onset of both PTDM and type 2 diabetes can be insidious and patients may be asymptomatic for years before symptoms present. Accordingly, PTDM management follows the conventional approach used for patients with type 2 diabetes ${ }^{[30]}$. PTDM is not always permanent and may stabilise within weeks or months ${ }^{[31]}$.

PTDM is a major problem among this population of patients as impaired glucose metabolism can contribute to increased risk of cardiovascular disease, subsequently reducing mortality in these patients.

\section{CNI induced diabetes}

The exact mechanism by which CNIs induce diabetes is unknown. One mechanism that has gained popularity involves calcineurin expression in pancreatic insulin-secreting $\beta$-cells. Here, calcineurin 
Table 1. Diagnostic criteria for diabetes and pre-diabetes (WHO, 2006)

\begin{tabular}{llll}
\hline Type of diagnostic test & Normal & Pre-diabetes & Diabetes \\
\hline Fasting glucose $(\mathrm{mmol} / \mathrm{L})$ & $<5.5$ & $5.5-7.0$ & $>7.0$ \\
Oral glucose tolerance test $(\mathrm{mmol} / \mathrm{L})$ & $<7.8$ & $7.8-11.1$ & $>11.1$ \\
$\mathrm{HbA1c}(\mathrm{mmol} / \mathrm{L})$ & $<42$ & $42-47$ & $>47$ \\
\hline
\end{tabular}

Table 2. Target CNI levels of heart transplant patients in the Golden Jubilee National Hospital, Glasgow

\begin{tabular}{|c|c|c|c|}
\hline Time after transplantation & $\begin{array}{c}\text { Tacrolimus }(\mu \mathrm{g} / \mathrm{L}) \text { target } \\
\text { therapeutic range }\end{array}$ & Time after transplantation & $\begin{array}{c}\text { Ciclosporin }(\mu \mathrm{g} / \mathrm{L}) \text { target } \\
\text { therapeutic range }\end{array}$ \\
\hline $0-3$ months & $10-15$ & 0-4 weeks & $240-300$ \\
\hline 3-6 months & $8-12$ & $1-6$ months & $160-200$ \\
\hline 6-12 months & $7-10$ & 6-12 months & $130-160$ \\
\hline$>12$ months & $5-7$ & $>12$ months & $64-96$ \\
\hline
\end{tabular}

undergoes a similar action to its role in T-cell activation. In pancreatic $\beta$-cells, the activation of calcineurin leads to the dephosphorisation and translocation of a different family of NFAT transcription factors. Following this, NFAT induces the expression of genes critical for multiple factors that control growth and hallmark $\beta$-cell functions, including insulin production and expression ${ }^{[19]}$. Therefore, calcineurin inhibition impairs $\beta$-cell proliferation and decreases $\beta$-cell mass resulting in reduced insulin expression. This ultimately leads to diabetes.

In heart transplantation, diabetes is a well-recognised complication. More than $22 \%$ of heart transplant patients develop diabetes 1 year after transplantation ${ }^{[12]}$. Immunosuppressive agents contribute to this morbidity. Nevertheless, evidence surrounding which CNI is more likely to negatively affect glucose metabolism is contradictory. It is understood that both tacrolimus and ciclosporin are equivalent in inducing diabetes but it is suggested that, in clinical practice, tacrolimus has greater diabetogenic potential ${ }^{[32]}$.

\section{METHODS}

\section{Study population}

A retrospective cohort study of 52 patients who underwent a first-time heart transplant at the Golden Jubilee National Hospital (Glasgow, Scotland) between January 2011 and August 2017. In January 2014, tacrolimus was made the primary $\mathrm{CNI}$ at the unit. As a result, 33 patients were on a tacrolimus-based maintenance regimen postoperatively. A comparable cohort of 19 patients on a ciclosporin-based maintenance regimen were selected. Prior to the investigation, one of the patients in the study population was diagnosed with diabetes. That patient was on a ciclosporin based regimen and included in the study. Patients who received changes in their drug regimens and patients who died were excluded. All patients were over the age of 18.

\section{Post-transplant Management}

Each patient received immunosuppression according to the unit's protocol. Immediate post-operative induction therapy consisted of rATG. This was given for up to 4 days after transplantation, until the patients kidney function is sufficient. Thereafter, patients received a combination regimen of CNI, MMF and a steroid. Patients remain on a CNI and MMF for their lifetime but steroids are removed 6 months after transplantation. Drug level monitoring was performed during routine follow-up visits at regular time intervals. Target CNI levels depend on time after transplantation, as illustrated in Table 2. These levels were collected and analysed in a laboratory at the Queen Elizabeth University Hospital, Glasgow, using tandem mass spectrometry.

\section{Data collection and outcomes measured}

Data was collected from the transplant unit's database. Clinical notes provided all the information necessary for analysis, including demographic information. Glucose metabolism was studied via fasting glucose levels 
Table 3. Selected demographic and baseline characteristics of the two patient groups

\begin{tabular}{|c|c|c|c|c|}
\hline & All $(n=52)$ & Tacrolimus \& MMF $(n=33)$ & Ciclosporin \& MMF $(n=19)$ & P-value \\
\hline Age & $50 \pm 13$ & $49 \pm 12$ & $51 \pm 14$ & 0.561 \\
\hline Male:female & $37: 15$ & $24: 9$ & $13: 6$ & 0.741 \\
\hline Body Mass Index $\left(\mathrm{kg} / \mathrm{m}^{2}\right)$ & $26.8 \pm 4.6$ & $25.4 \pm 4.5$ & $26.8 \pm 4.8$ & 0.103 \\
\hline Preoperative Diabetics & 5 & $4(12)$ & $1(5)$ & 0.641 \\
\hline Creatinine & $115.7 \pm 40.3$ & $119 \pm 46.2$ & $109.9 \pm 27.3$ & 0.440 \\
\hline $\begin{array}{l}\text { Pre-transplant diagnosis } \\
\text { DCM } \\
\text { HCM } \\
\text { IHD } \\
\text { Other }\end{array}$ & $\begin{array}{l}32 \\
4 \\
9 \\
7\end{array}$ & $\begin{array}{l}18(55) \\
3(9) \\
6(18) \\
6(18)\end{array}$ & $\begin{array}{l}14(74) \\
1(5) \\
3(16) \\
1(5)\end{array}$ & 0.479 \\
\hline
\end{tabular}

Table 4. Fasting glucose levels of the two cohorts over time

\begin{tabular}{lccc}
\hline Fasting glucose $(\mathbf{m m o l} / \mathbf{L})$ & Tacrolimus \& MMF $(\boldsymbol{n}=\mathbf{3 3})$ (mean \pm SD) & Ciclosporin \& MMF $(\boldsymbol{n}=\mathbf{1 9})(\mathbf{M e a n} \pm \mathbf{S D})$ & $\boldsymbol{P}$-value \\
\hline BASELINE & $5.9 \pm 1.3$ & $5.4 \pm 0.9$ & 0.726 \\
1 month & $6.4 \pm 1.7$ & $5.5 \pm 1.3$ & 0.064 \\
3 months & $7.8 \pm 6.3$ & $6.1 \pm 1.6$ & 0.275 \\
6 months & $8.8 \pm 7.5$ & $5.9 \pm 1.3$ & 0.102 \\
9 months & $6.9 \pm 2.0$ & $5.4 \pm 1.4$ & 0.013 \\
12 months & $6.7 \pm 3.7$ & $6.5 \pm 1.9$ & 0.836 \\
\hline
\end{tabular}

and HbA1c. Fasting glucose levels were collected from five points in time; 1, 3, 6, 9 and 12 months postoperatively. HbA1c was collected at one follow-up visit. The time points were chosen according to the postoperative follow-up protocol used by the unit, this was consistent between patients.

\section{Statistical analysis}

Data was extracted, collated and stored on a Microsoft Excel 2017 spreadsheet. This data was then imported into Prism 7.0c software application for statistical analysis. Independent $t$-test was used to analyse any differences in continuous data and the Chi-squared test was used for categorical data. The level of significance was set at $P$-value $<0.05$.

\section{RESULTS}

\section{Patient demographics}

Patient characteristics are listed in Table 3. The study groups were not matched, but all had appropriate clinical records and information that was accessible, allowing comparisons to be made. There was no statistical significant difference in the patient baseline characteristics, including age, gender and pretransplant diagnosis. Of the 52 patients enrolled, 5 had a diagnosis of diabetes, 4 of which were on a tacrolimus-based regimen and diagnosed after transplantation.

\section{Laboratory Blood Glucose measurements}

As mentioned previously, fasting glucose of the study population was collected at five different points of time postoperatively. This data was collated into a mean fasting glucose for each time-period, the results of which are presented in Table 4. At one month postoperatively, there was no statistical difference in fasting glucose between the two cohorts. Here, fasting glucose for the TAC cohort was $6.4 \pm 1.7 \mathrm{mmol} / \mathrm{L}$ and $5.5 \pm 1.3 \mathrm{mmol} / \mathrm{L}$ for the CyA cohort $(P=0.064)$. A fasting glucose of $6.4 \mathrm{mmol} / \mathrm{L}$ suggests TAC patients were pre-diabetic at 1 month [Table 1].

In the first six months, there was a rise in fasting glucose among the TAC cohort, with levels peaking at the 6-month follow-up. The fasting glucose of the TAC group at this stage was $8.8 \mathrm{mmol} / \mathrm{L}$. This greatly exceeds 


\section{Fasting glucose of patients on tacrolimus or ciclosporin}

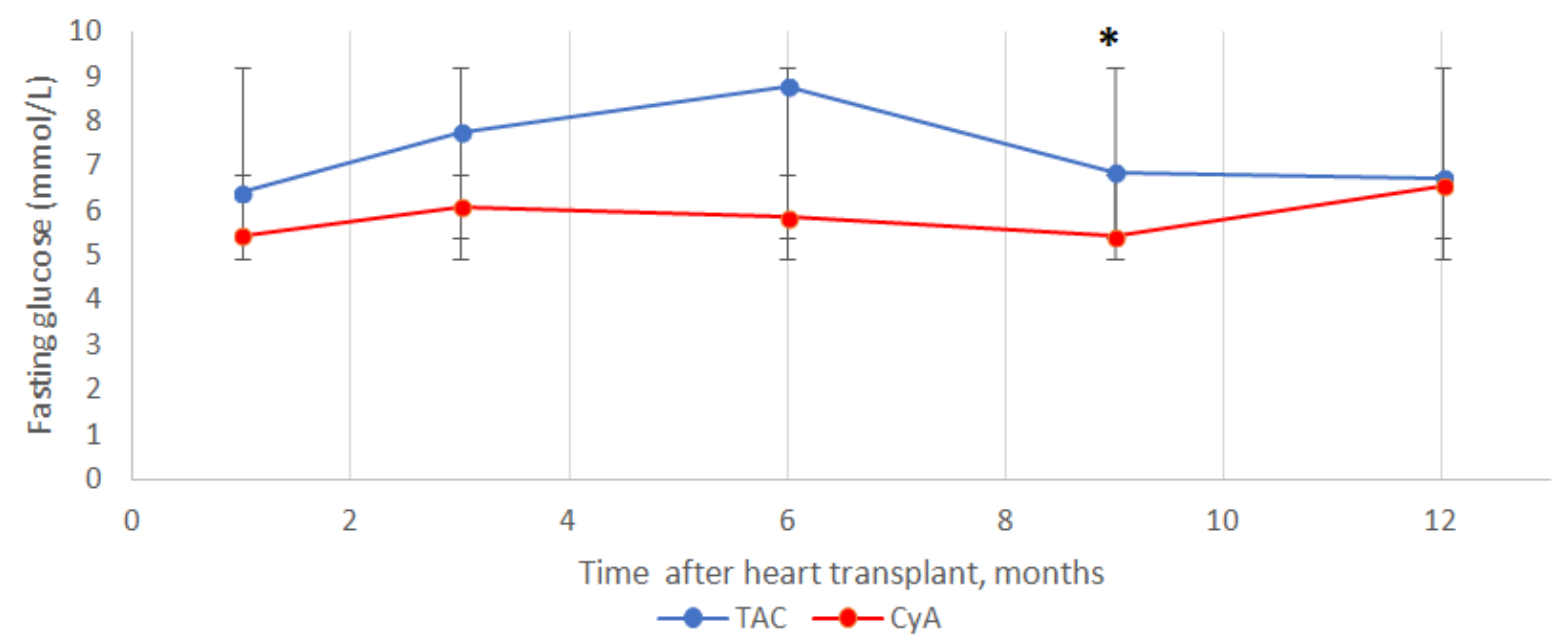

Figure 2. Fasting blood glucose of heart transplant patients on tacrolimus or ciclosporin maintenance immunosuppression over time postoperatively (mean $\pm \mathrm{SD}$ ). At 9 months $P=0.013$

the diagnostic range for diabetes. The 6-month point also marks the largest difference between the two cohorts across the 12-month period, $8.8 \pm 7.5 \mathrm{mmol} / \mathrm{L} v s .5 .9 \pm 1.3 \mathrm{mmol} / \mathrm{L}(P=0.102)$, this is highlighted in Figure 2.

During the first year after transplantation, drug dosage is monitored and adjusted cautiously according to the transplant unit's target levels, incidence of transplant rejection and any side effects which may present, such as hyperglycaemia. Patients experiencing hyperglycaemia are followed up and managed according to the unit's protocol. This includes reducing drug target levels for CNIs and providing appropriate management for the unbalanced glucose metabolism.

Moreover, after 6-months fasting glucose declines across the population; this is especially seen in the TAC group. The difference in mean between the two cohorts shows significance at 9 months postoperatively, with the TAC cohort showing higher values. The mean fasting glucose was $6.9 \pm 2.0 \mathrm{mmol} / \mathrm{L}$ in the TAC group and $5.4 \pm 1.4 \mathrm{mmol} / \mathrm{L}$ in the CyA group $(P=0.013)$.

One year after transplantation, mean fasting glucose of TAC cohort continued to decline. However, levels are still considered pre-diabetic and values are above the CyA group, $6.7 \pm 3.7 \mathrm{mmol} / \mathrm{L} v s .6 .5 \pm 1.9 \mathrm{mmol} / \mathrm{L}$ $(P=0.836)$. Nevertheless, the 12 -month follow-up marks the highest mean fasting glucose levels for the CyA cohort. Consequently, CyA could possess a diabetogenic potential 12 months after transplantation.

Overall, the mean fasting glucose over the 12-month period indicated significance. TAC treated patients had a higher mean fasting glucose, $7.3 \pm 1.0 \mathrm{mmol} / \mathrm{L}$, compared to the CyA cohort, $5.9 \pm 0.5 \mathrm{mmol} / \mathrm{L}(P=0.017)$.

In contrast to the fasting glucose results, mean $\mathrm{HbA1c}$ of the TAC group was lower than the CyA group, as shown in Figure 3. These results however, did not reach statistical significance $(P=0.104)$. The mean HbA1c was collated from information at one interval for patients on both regimens. According to the diagnostic criteria [Table 1], CyA treated patients are pre-diabetic whilst TAC treated patients are not at risk of diabetes. 


\section{$\mathrm{HbA1c}$ of patients on tacrolimus or ciclosporin}

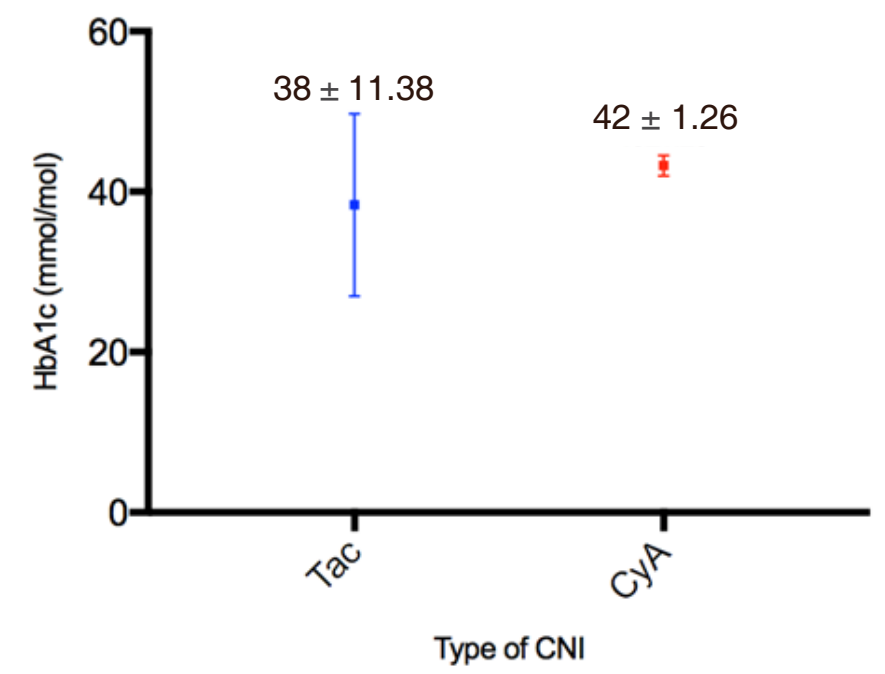

Figure 3. $\mathrm{HbA1c}$ of heart transplant patients on tacrolimus or ciclosporin at one time interval (mean \pm SD)

\section{DISCUSSION}

\section{Principle findings}

This study confirmed the risk of post-transplant diabetes is worse in heart transplant patients treated with tacrolimus-based maintenance immunosuppression compared with those treated with ciclosporin, when using mean fasting glucose as an indicator. The difference was significant at 9 months post-operatively. This timing fits with changes in the unit's drug regimen, especially the removal of corticosteroids which also contribute to altered glucose metabolism. In both cohorts, fasting glucose normalises at 12 months, further emphasising the role of corticosteroids in the results produced.

The mean HbA1c was greater in the ciclosporin treated cohort. At the beginning of the study, the two cohorts were comparable, with many relevant contributors to post-transplant diabetes considered- including age, sex, weight, creatinine, pretransplant diagnosis and diagnosis of diabetes.

\section{Context of research}

Much evidence involving the effectiveness of both tacrolimus and ciclosporin is based on data from kidney and liver transplantation. For that reason, Reichart et al. ${ }^{[33]}$ (2001) conducted a large European multicentre study to investigate the effectiveness of both CNIs in heart transplant recipients. With a study population of 82 patients across 5 centres, they found that when combined with azathioprine and corticosteroids, tacrolimus was just as effective as ciclosporin. While this three-year follow up confirmed tacrolimus a viable alternative for ciclosporin in heart transplantation, Reichart and colleagues also observed a higher proportion of patients treated with tacrolimus requiring insulin for PTDM, a consequence that would affect the morbidity and mortality of patients in years to come ${ }^{[33]}$.

Another multicentre study published a few months later Taylor et al. ${ }^{[34]}$ (1999) compared tacrolimus and ciclosporin to find both equally safe and effective maintenance immunosuppression in heart transplantation. They did observe a higher rate of hypertension and hyperlipidaemia in patients receiving tacrolimus. This was a significant finding as both hypertension and hyperlipidaemia negatively impact renal function. There was also no difference in the incidence of diabetes or hyperglycaemia between the two groups. This, at the time, differed from liver and kidney trials where diabetes was significantly more common in tacrolimus 
treated patients. The results of this study confirmed the advantages of tacrolimus over ciclosporin.

Early studies used a combination of azathioprine and corticosteroids with either tacrolimus or ciclosporin. Nevertheless, since its use in the first heart transplant operation, treatment with azathioprine has been replaced in clinical practice by MMF due to its increased toxicity. An early investigation into the substitution of MMF for azathioprine found that in 650 heart transplant patients, MMF was more effective in reducing mortality and rejection and was associated with decreased toxicity ${ }^{[18]}$. In the 2000 's, Kobashigawa and colleagues further investigated this area. They found that a combination of tacrolimus and MMF offered more advantages than ciclosporin and MMF in cardiac transplant patients, including fewer rejections and an improved side effect profile. Post-transplant diabetic rates were greater among the tacrolimus and MMF treated group, although this difference was not statistically significant ${ }^{[35]}$. The PTDM results Kobashigawa produced reflect similarity with the current study.

In the studies mentioned above, all patients are followed for a short time interval. Trials comparing triple immunosuppressive strategies involving tacrolimus or ciclosporin with MMF and steroids over a long term are rarely published. Guethoff et al ${ }^{[36]}$ (2013) used prospective randomised trial to follow-up heart transplant patients over 10 years. Long term analysis found a lower incidence of rejection in the tacrolimus group, but there was no difference between groups in long-term survival ${ }^{[36]}$.

Clinical trials have been principle to the success of heart transplantation. Despite the vast number of trials, there is no single validated immunosuppression regimen. Nevertheless, protocols used worldwide in 2017 are strongly influenced by the results of SYMPHONY study which demonstrated that a low dose of tacrolimus, MMF and corticosteroids had the best allograft outcomes ${ }^{[37]}$.

Since the superior rejection profile of tacrolimus has been established, research has been directed towards the side effects produced by the two CNIs and the consequences of this. However, there is limited data surrounding the onset of diabetes after tacrolimus or ciclosporin treatment in cardiac transplant patients. A large European multicentre trial published by Grimm et al ${ }^{[38]}$ (2006) revealed the incidence of PTDM in heart transplantation was significantly higher in the tacrolimus group. Accordingly, more tacrolimus patients required insulin therapy ${ }^{[38]}$.

Grimm et al. ${ }^{[38]}$ s results highlighting the diabetogenic potential of tacrolimus, it should be noted that published studies in this area have often failed to reach significance to due low patient numbers. A study by Teebken et al ${ }^{[39]}$ (2002) reflects this, as out of 32 heart transplant recipients, 4 patients treated with tacrolimus developed PTDM compared with 1 patient treated with ciclosporin. The small sample size makes these results difficult to statistically analyse and compare.

Corticosteroids are also associated with a greater risk of developing diabetes after heart transplantation. Heart transplant recipients developing diabetes were found to be receiving higher mean doses of prednisolone compared to those without the condition ${ }^{[40]}$. Consequently, an increased number of studies are considering the effect of corticosteroid-sparing and corticosteroid-free regimens on the development of PTDM. Baran et al..$^{[41]}$ (2002) have shown that tapering of and weaning patients from corticosteroid treatment considerably lowered the incidence of diabetes.

\section{Impact of PTDM on heart transplantation}

PTDM has been a recognised complication of transplantation for several years, despite this, the importance of the condition has been underestimated. In the general population, it is putative that diabetes increases risk of cardiovascular disease (CVD). Nonetheless, the complications associated with diabetes were not thought to be a concern for patients who had undergone heart transplantation. Initial studies into the effect of PTDM 
on transplant patients focused on kidney transplantation. Lindholm et al. ${ }^{[42]}$ (1995) demonstrated that PTDM increased the risk of CVD in transplant recipients. The relationship between PTDM and CVD is a concern in heart transplant patients, as these patients are already at risk of CAV. As previously mentioned, CAV is an accelerated form of coronary artery disease, it is also a major cause of death in patients surviving over a year after heart transplantation ${ }^{[43]}$.

A study by Kato et al. ${ }^{[4]]}$ (2004) looked at the relationship between glucose intolerance and CVD in 151 heart transplant recipients. The researchers used HbAlc as an indicator of glucose metabolism and found that increased HbA1c levels were associated with occurrence of CVD and could play a pivotal role in its pathogenesis ${ }^{[4]}$. A limitation of this study and many others in this area is the lack of information surrounding the outcome of CVD in this population of patients. While it is important for clinicians to recognise the link between PTDM and CVD, the management and consequences of this need to be addressed.

Individuals with prediabetes are also at risk of CVD. Elevated fasting glucose among this group results from both impaired insulin action and secretion ${ }^{[45]}$. A meta-analysis comprising 1,611,399 individuals conducted by Huang et al. ${ }^{[46]}$ (2016) found that prediabetes was associated with increased risk of composite cardiovascular events which all lead to mortality. They also observed increased risk occurring when fasting glucose was as low as $5.6 \mathrm{mmol} / \mathrm{L}$.

In this study, it has been shown that patients on tacrolimus were prediabetic throughout the duration of the trial, with levels considerably higher than $5.6 \mathrm{mmol} / \mathrm{L}$. It is therefore essential to not only focus on a blood test for diagnosis of diabetes but also any symptoms a patient may be experiencing. However, the study published by Huang et al. ${ }^{[46]}$ consisted of data that was not specific to the transplant field. It is therefore difficult to generalise Huang's results to the current study's population of patients. There is scope for research in this area as data regarding the cardiovascular implications of prediabetes in heart transplant patients is lacking.

\section{Limitations of the study}

Retrospective studies are prone to limitations which can affect the reliability of any results and conclusions produced. This study is prone to selection bias as data used was collected from patient files, as a result there was no participation selection.

The data for this study was collected from patient files where information was transplant specific. Therefore, data that could influence the risk of diabetes was not measured, such as family history of diabetes and ethnicity. Ideally, HbA1c would be collected at different time points after transplantation. However, there was only one measurement available for both cohorts and so it is difficult to compare the results of the mean fasting glucose and HbA1c.

The use of a steroid in immunosuppressive maintenance therapy is a significant confounding factor in this study. As mentioned previously, a common side effect of steroid use is hyperglycaemia. Patients were followed up for a 12-month period, so fluctuating fasting glucose levels seen may be a result of steroid use. As steroids are removed from the regimen at 6 months, following up patients for a longer period could eliminate this cofounding variable.

As well as a short follow up, this was a single centre study consisting of 52 patients. These factors can create lack of external validity as results are difficult to generalise. Nonetheless, because the study was carried out in one unit, all patients received similar care, similar selection for surgery, drug regimens and follow-up. These factors give validity to the findings of this study. 
Due to the nature of this study, follow-up times were not exactly on time for each patient, but for this study, flexibility of two weeks was allowed in data collection. All information was readily available and there were no technical difficulties faced during this study.

\section{Implications}

Understanding the risk of hyperglycaemia with different maintenance immunosuppressant regimens is very important as chronic hyperglycaemia can negatively affect a patient's quality of life and can result in high morbidity and mortality. A major modifiable risk factor for the development of PTDM is immunosuppression, but risk versus benefit analysis is needed to balance the risk of developing PTDM versus rejection. This study does not support the view of switching patients from tacrolimus to ciclosporin. Rejection episodes and survival data collection were not included in the study; therefore, this study cannot comment on the superiority of one drug over the other.

Instead, implications lie in informing clinicians about the possibility of developing diabetes after tacrolimus use and the complications of this on patients. Therefore, greater attention should be paid to recognising diabetes through different glycaemic parameters. As a result of the findings of this study, the heart transplant unit at the Golden Jubilee National Hospital has introduced regular HbAic testing in all heart transplant patients. A HbAic diagnosis of diabetes is already endorsed in the general population and should be used to recognise PTDM, especially due to its ability to predict diabetic complications.

Hyperglycaemia is extremely common in the early postoperative period. It can also occur because of critical conditions such as infections or as a consequence of rejection therapy. In this study, there is no data on patient glucose metabolism before transplantation. This would be helpful when making a formal diagnosis of PTDM, as the patient's pre-transplant glucose function can be compared to after transplantation when they are stable on their maintenance immunosuppression, have stable cardiac allograft function and no acute infections.

Further studies should consider collaborating and combining data that links fasting glucose and HbA1c with end points, including microvascular complications, cardiovascular events, patient and graft survival. There is also a need to facilitate clinical trials into the prevention of PTDM, one way by which this can be done is to identify patients at risk. A limitation of this study, as mentioned previously, is the lack of data. Patient risk factors for PTDM are well established and encompass general information such as family history of diabetes. There is a room for possibly preventing PTDM and its complications when such factors are collected.

The future of pharmacological management in transplant recipients is beyond calcineurin inhibitors. Based on this research and personal recommendation, more advanced immunological methods could reduce sideeffects produced currently. This could also help reach the ultimate goal of organ transplantation, which is the development of safe and effective regimens that manipulate host immune system into accepting transplanting organs in absence of immunosuppressive management or 'tolerance'. This would prevent the morbidity of chronic immunosuppression including CVD. Nevertheless, CNIs have dominated transplantation for decades through targeting T-cells, a key player in rejection. Research surrounding the function and clinical effects of both tacrolimus and ciclosporin will be valuable for the manipulation of immune cells in the future.

In conclusion, both tacrolimus and ciclosporin continue to remain at the backbone of pharmacological management in heart transplant patients. Even though tacrolimus is a newer agent with a greater ability to prevent allograft rejection, patients are at increased risk of diabetes. Pharmacological development in this area is required as the gap between the need for cardiac transplantations worldwide and the development of effective immunosuppressant regimens is growing. A heart transplantation can transform a patient's life, 
but this significant procedure can be jeopardised by co-morbidities associated with its management. As a result, a new heart may fail for the same reasons the original heart failed.

\section{DECLARATIONS}

\section{Authors' contributions}

Data collection, data analysis, manuscript writing: Jagpal A

Statistical analysis, manuscript review: Das De S

Manuscript editing and reviewing: Avtaar Singh SS

Study supervisor, manuscript reviewing: Kirk A

\section{Availability of data and materials}

At request. Kindly email corresponding author.

\section{Financial support and sponsorship}

None.

\section{Conflicts of interest}

All authors declare that there are no conflicts of interest.

\section{Ethical approval and consent to participate}

This report is not considered research by the NHS, as defined by the UK Policy Framework for Health and Social Care Research. Therefore, this study did not require approval from an NHS Research Ethics Committee (REC).

\section{Consent for publication}

Not applicable.

\section{Copyright}

(C) The Author(s) 2018.

\section{REFERENCES}

1. Barnard CN. The operation. A human cardiac transplant: an interim report of a successful operation performed at Groote Schuur Hospital, Cape Town. S Afr Med J 1967;41:1271-4.

2. Stehlik J, Edwards LB, Kucheryavaya AY, Benden C, Christie JD, Dipchand AI, Dobbels F, Kirk R, Rahmel AO, Hertz MI; International Society of Heart and Lung Transplantation. The Registry of the International Society for Heart and Lung Transplantation: 29th official adult heart transplant report--2012. J Heart Lung Transplant 2012;31:1052-64.

3. Caves PK, Stinson EB, Billingham M, Shumway NE. Percutaneous transvenous endomyocardial biopsy in human heart recipients. Ann Thorac Surg 1973;16:325-36.

4. Billingham ME. Endomyocardial biopsy detection of acute rejection in cardiac allograft recipients. Heart Vessels Suppl 1985;1:86-90.

5. NHS. Organ donation and transplantation- activity (1)s for the UK as at April 2017. NHS blood ant transplantation activity 2017. Available from: https://www.organdonation.nhs.uk/supporting-my-decision/statistics-about-organ-donation/transplant-activity-report/. [Last accessed on 12 Sep 2018]

6. NHS. Annual report on cardiothoracic transplantation. NHS Blood ant Transplantation Activity 2015. Available from: https://www. organdonation.nhs.uk/supporting-my-decision/statistics-about-organ-donation/transplant-activity-report/. [Last accessed on $12 \mathrm{Sep}$ 2018]

7. Tonsho M, Michel S, Ahmed Z, Alessandrini A, Madsen JC. Heart transplantation: challenges facing the field. Cold Spring Harb Perspect Med 2014;4: pii: a015636.

8. Ayala Garcia MA, Gonzalez Yebra B, Lopez Flores AL, Guani Guerra E. The major histocompatibility complex in transplantation. J Transplant 2012;2012:842141.

9. Heit JJ, Apelqvist AA, Gu X, Winslow MM, Neilson JR, Crabtree GR, Kim SK. Calcineurin/NFAT signalling regulates pancreatic betacell growth and function. Nature 2006;443:345-9. 
10. Friend PJ. Rejection reactions to different organ transplants. Eye 1995;9:190.

11. Azuma H, Tilney NL. Chronic graft rejection. Curr Opin Immunol 1994;6:770-6.

12. Lund LH, Khush KK, Cherikh WS, Goldfarb S, Kucheryavaya AY, Levvey BJ, Meiser B, Rossano JW, Chambers DC, Yusen RD, Stehlik J; International Society for Heart and Lung Transplantation. The Registry of the International Society for Heart and Lung Transplantation: thirty-fourthadult heart transplantation report-2017; focus theme: allograft ischemic time. J Heart Lung Transplant 2017;36:1037-46.

13. Lindenfeld J, Miller GG, Shakar SF, Zolty R, Lowes BD, Wolfel EE, Mestroni L, Page RL 2nd, Kobashigawa J. Drug therapy in the heart transplant recipient: part II: immunosuppressive drugs. Circulation 2004;110:3858-65.

14. Steiner RW, Awdishu L. Steroids in kidney transplant patients. Semin Immunopathol 2011;33:157-67.

15. Elion GB. The George Hitchings and Gertrude Elion Lecture. The pharmacology of azathioprine. Ann N Y Acad Sci 1993;685:400-7.

16. Wiseman AC. Immunosuppressive medications. Clin J Am Soc Nephrol 2016;11:332-43.

17. Costanzo MR, Dipchand A, Starling R, Anderson A, Chan M, Desai S, Fedson S, Fisher P, Gonzales-Stawinski G, Martinelli L, McGiffin D, Smith J, Taylor D, Meiser B, Webber S, Baran D, Carboni M, Dengler T, Feldman D, Frigerio M, Kfoury A, Kim D, Kobashigawa J, Shullo M, Stehlik J, Teuteberg J, Uber P, Zuckermann A, Hunt S, Burch M, Bhat G, Canter C, Chinnock R, CrespoLeiro M, Delgado R, Dobbels F, Grady K, Kao W, Lamour J, Parry G, Patel J, Pini D, Towbin J, Wolfel G, Delgado D, Eisen H, Goldberg L, Hosenpud J, Johnson M, Keogh A, Lewis C, O’Connell J, Rogers J, Ross H, Russell S, Vanhaecke J; International Society of Heart and Lung Transplantation Guidelines. The International Society of Heart and Lung Transplantation Guidelines for the care of heart transplant recipients. J Heart Lung Transplant 2010;29:914-56.

18. Kobashigawa J, Miller L, Renlund D, Mentzer R, Alderman E, Bourge R, Costanzo M, Eisen H, Dureau G, Ratkovec R, Hummel M, Ipe D, Johnson J, Keogh A, Mamelok R, Mancini D, Smart F, Valantine H. A randomized active-controlled trial of mycophenolate mofetil in heart transplant recipients. Mycophenolate mofetil investigators. Transplantation 1998;66:507-15.

19. Snell GI, Levvey BJ, Chin W, Kotsimbos T, Whitford H, Waters KN, Richardson M, Williams TJ. Sirolimus allows renal recovery in lung and heart transplant recipients with chronic renal impairment. J Heart Lung Transplant 2002;21:540-6.

20. Colombo D, Ammirati E. Cyclosporine in transplantation - a history of converging timelines. J Biol Regul Homeost Agents 2011;25:493-504.

21. Eisen HJ, Hobbs RE, Davis SF, Carrier M, Mancini DM, Smith A, Valantine H, Ventura H, Mehra M, Vachiery JL, Rayburn BK, Canver CC, Laufer G, Costanzo MR, Copeland J, Dureau G, Frazier OH, Dorent R, Hauptman PJ, Kells C, Masters R, Michaud JL, Paradis I, Renlund DG, Vanhaecke J, Mellein B, Mueller EA. Safety, tolerability, and efficacy of cyclosporine microemulsion in heart transplant recipients: a randomized, multicenter, double-blind comparison with the oil-based formulation of cyclosporine--results at 24 months after transplantation. Transplantation 2001;71:70-8.

22. Watson CJ, Dark JH. Organ transplantation: historical perspective and current practice. Br J Anaesth 2012;108 Suppl 1:i29-42.

23. Fung JJ. Tacrolimus and transplantation: a decade in review. Transplantation 2004;77:S41-3.

24. Meiser BM, Groetzner J, Kaczmarek I, Landwehr P, Müller M, Jung S, Uberfuhr P, Fraunberger P, Stempfle HU, Weis M, Reichart B. Tacrolimus or cyclosporine: which is the better partner for mycophenolate mofetil in heart transplant recipients? Transplantation 2004;78:591-8.

25. Armitage JM, Kormos RL, Griffith BP, Hardesty RL, Fricker FJ, Stuart RS, Marrone GC, Todo S, Fung J, Starzl TE. A clinical trial of FK 506 as primary and rescue immunosuppression in cardiac transplantation. Transplant Proc 1991;23:1149-52.

26. Mukherjee S, Mukherjee U. A comprehensive review of immunosuppression used for liver transplantation. J Transplant 2009;2009:701464.

27. WHO. Definition and diagnosis of diabetes mellitus and intermediate hyperglycaemia. WHO: Geneva, Switzerland 2006.

28. Excellence NIfHaC. Type 2 diabetes: prevention in people at high risk. NICE guideline (PH38), 2012.

29. Sharif A, Cohney S. Post-transplantation diabetes-state of the art. Lancet Diabetes Endocrinol 2016;4:337-49.

30. Pham PT, Pham PM, Pham SV, Pham PA, Pham PC. New onset diabetes after transplantation (NODAT): an overview. Diabetes Metab Syndr Obes 2011;4:175-86.

31. Davidson J, Wilkinson A, Dantal J, Dotta F, Haller H, Hernández D, Kasiske BL, Kiberd B, Krentz A, Legendre C, Marchetti P, Markell M, van der Woude FJ, Wheeler DC; International Expert Panel. New-onset diabetes after transplantation: 2003 international consensus guidelines. Proceedings of an international expert panel meeting. Barcelona, Spain, 19 February 2003. Transplantation 2003;75:SS3-24.

32. Velleca A, Kittleson M, Patel J, Rafiei M, Osborne A, Ngan A, Hage A, Chang DH, Czer L, Kobashigawa J. Tacrolimus-versus cyclosporine-induced diabetes leads to more diabetic complications after heart transplantation. J Heart Lung Transplant 2013;32:S202.

33. Reichart B, Meiser B, Viganò M, Rinaldi M, Yacoub M, Banner NR, Gandjbakhch I, Dorent R, Hetzer R, Hummel M. European multicenter tacrolimus heart pilot study: three year follow-up. J Heart Lung Transplant 2001;20:249-50.

34. Taylor DO, Barr ML, Radovancevic B, Renlund DG, Mentzer RM Jr, Smart FW, Tolman DE, Frazier OH, Young JB, VanVeldhuisen P. A randomized, multicenter comparison of tacrolimus and cyclosporine immunosuppressiveregimens in cardiac transplantation: decreased hyperlipidemia and hypertension with tacrolimus. J Heart Lung Transplant 1999;18:336-45.

35. Kobashigawa JA, Miller LW, Russell SD, Ewald GA, Zucker MJ, Goldberg LR, Eisen HJ, Salm K, Tolzman D, Gao J, Fitzsimmons W, First R; the Study Investigators. Tacrolimus with mycophenolate mofetil (MMF) or sirolimus vs. cyclosporine with MMF in cardiac transplant patients: 1-year report. Am J Transplant 2006;6:1377-86.

36. Guethoff S, Meiser BM, Groetzner J, Eifert S, Grinninger C, Ueberfuhr P, Reichart B, Hagl C, Kaczmarek I. Ten-year results of a randomized trial comparing tacrolimus versus cyclosporine a in combination with mycophenolate mofetil after heart transplantation. Transplantation 2013;95:629-34. 
37. Ekberg H, Tedesco-Silva H, Demirbas A, Vitko S, Nashan B, Gurkan A, Margreiter R, Hugo C, Grinyo JM, Frei U, Vanrenterghem Y, Daloze P, Halloran PF. Reduced exposure to calcineurin inhibitors in renal transplantation. N Engl J Med 2007; 357:2562-75.

38. Grimm M, Rinaldi M, Yonan NA, Arpesella G, Arizón Del Prado JM, Pulpón LA, Villemot JP, Frigerio M, Rodriguez Lambert JL, Crespo-Leiro MG, Almenar L, Duveau D, Ordonez-Fernandez A, Gandjbakhch J, Maccherini M, Laufer G. Superior prevention of acute rejection by tacrolimus vs. cyclosporine in heart transplant recipients--a large European trial. Am J Transplant 2006;6:1387-97.

39. Teebken OE, Strüber M, Harringer W, Pichlmaier MA, Haverich A. Primary immunosuppression with tacrolimus and mycophenolate mofetil versus cyclosporine and azathioprine in hearttransplant recipients. Transplant Proc 2002;34:1265-8.

40. Depczynski B, Daly B, Campbell LV, Chisholm DJ, Keogh A. Predicting the occurrence of diabetes mellitus in recipients of heart transplants. Diabet Med 2000;17:15-9.

41. Baran DA, Ashkar J, Galin ID, Sandler D, Segura L, Courtney MC, Correa R, Chan M, Lansman SL, Spielvogel D, Cheng J, Gass AL. Tacrolimus and new onset diabetes mellitus: the effect of steroid weaning. Transplant Proc 2002;34:1711-2.

42. Lindholm A, Albrechtsen D, Frodin L, Tufveson G, Persson NH, Lundgren G. Ischemic heart disease--major cause of death and graft loss after renal transplantation in Scandinavia. Transplantation 1995;60:451-7.

43. Prada-Delgado O, Estevez-Loureiro R, Paniagua-Martin MJ, Lopez-Sainz A, Crespo-Leiro MG. Prevalence and prognostic value of cardiac allograft vasculopathy 1 year after heart transplantation according to the ISHLT recommended nomenclature. J Heart Lung Transplant 2012;31:332-3.

44. Kato T, Chan MC, Gao SZ, Schroeder JS, Yokota M, Murohara T, Iwase M, Noda A, Hunt SA, Valantine HA. Glucose intolerance, as reflected by hemoglobin A1c level, is associated with the incidence and severity of transplant coronary artery disease. J Am Coll Cardiol 2004;43:1034-41.

45. Laakso M. Cardiovascular disease in type 2 diabetes from population to man to mechanisms: the Kelly West Award Lecture 2008. Diabetes Care 2010;33:442-9.

46. Huang Y, Cai X, Mai W, Li M, Hu Y. Association between prediabetes and risk of cardiovascular disease and all cause mortality: systematic review and meta-analysis. BMJ 2016;355:i5953. 